\title{
Histomorphometric characteristics of the tibialis anterior muscle and the peroneal nerve in experimental repair of post-resection tibial defect using the llizarov external fixation and the Masquelet technique
}

\author{
D.S. Mokhovikov' ${ }^{1}$ T.A. Stupina ${ }^{1}$, T.N. Varsegova ${ }^{1}$, O.V. Diuriagina ${ }^{1}$, A.A. Emanov ${ }^{1}$, D.Yu. Borzunov ${ }^{2,3}$ \\ ${ }^{1}$ Ilizarov National Medical Research Centre for Traumatology and Orthopedics, Kurgan, Russian Federation \\ ${ }^{2}$ Ural State Medical University, Ekaterinburg, Russian Federation \\ ${ }^{3}$ Central City Clinical Hospital, Ekaterinburg, Russian Federation
}

\begin{abstract}
Objective Explore structural changes in the tibialis anterior muscle (TAM) and the peroneal nerve (PN) in repair of postresection tibial defect using the Ilizarov external fixation and a cement spacer. Material and methods A defect-nonunion was simulated in the proximal tibia of 10 mongrels using the Ilizarov external fixation followed by use of a cement spacer to fill the $2.5 \mathrm{~cm}$ defect-diastasis. The spacer was removed after 30 days and tibia distraction commenced with the rate of 1 $\mathrm{mm}$ performed 4 times/day following transverse osteotomy in the distal tibia to achieve docking of bone fragments. Animals were sacrificed after 60-day fixation (F60) and 30 days after frame removal (FR30). Histomorphometric parameters of the TAM and PN samples were examined. Results TAM appeared to be denervated with death or decreased size of myons and angular contours noted at F60 and FR30. Degenerated and intact muscle fibers (MF) were shown to increase by $32.5 \%$ and by $1 \%$, respectively, at FR30. The peak of histogram distributing MF by diameters at F60 indicated to ischemic muscles, and a 2-fold decrease in muscle diameter and the histogram skewed to the left by 4 classes showed increase in muscle atrophy at FR30. Reactive destructive changes were noted in at least $5.4 \%$ of myelinated nerve fibres of the PN at F60 and FR30. A 1.6-to-1.7 times decrease in larger and a 1.6-to-1.8 times increase in smaller fibers, the presence of regenerative clusters indicated to previous destruction of a large number of motor and sensory nerves. Changes in the population structure, destruction of myelinated fibers and loss of non-myelinated fibers were associated with obliteration of epineurial vessels and loss of endoneurial capillaries at F60. Conclusion Reactive destructive changes in the TAM and PN revealed in bone defects repaired with the Ilizarov external fixation and the Masquelet technique should be considered in planning of postoperative pharmacologic thearapy and rehabilitation.

Keywords: tibial defect, Masquelet technique, tibialis anterior muscle, peroneal nerve, histomorphometry
\end{abstract}

\section{INTRODUCTION}

The Masquelet-induced-membrane technique [1] has initiated the new era for management of nonunions $[2,3,4]$ that is still a clinical challenge. This is a twostage surgical technique for reconstruction of bone defects radically addressing the problem by total excision of defective bone tissue and the induction of a periosteal membrane $[1,3,5]$. With wide applications of the Masquelet technique, remarkable advances have been made in management of septic (trauma, osteomyelitis) [4, 6, 7, 8, 9] or aseptic (trauma, cancer, congenital pseudarthrosis) $[10,11,12]$ bone defects [2]. Congenital pseudarthrosis and tumours were most common etiopathogenetic factors [13], and tibia and femur were most commonly involved segments $[13,14$, 15]. Antimicrobial additives and coatings, various types of bone grafts, resection and fixation techniques $[2,3$,
4], and additional bone plasty interventions [10] used by clinicians have opened new perspectives in management of bone defects with the Masquelet technique. The induced-membrane technique used in conjunction with the Ilizarov non-free bone plasty method allowed for reliable bone consolidation of congenital pseudarthrosis of the tibia with no recurrence of pseudarthrosis [10]. Rehabilitation of patients with congenital pseudarthrosis of the tibia is an essential issue. We sought to investigate muscles and nerves that play a role in the limb functional recovery following a radical operative intervention with the lack of data on the matter in the existing literature.

The purpose of the study was to explore structural changes in the tibialis anterior muscle and the peroneal nerve in experimental repair of postresection tibial defect using the Ilizarov external fixation and a cement spacer.

\section{MATERIAL AND METHODS}

The experiment was carried out on 10 mongrels that underwent three operative interventions. The average body weight of the subjects was $16.8 \pm 0.4 \mathrm{~kg}$, the age averaged $3.9 \pm 0.3$ years and tibia length ranged from $17 \mathrm{~cm}$ to $20 \mathrm{~cm}$. A defect-nonunion was simulated in the proximal tibia of the subjects using the Ilizarov external fixation (patent № $2539627 \mathrm{RF}$ «Technique of simulating a long bone defect-nonunion»). Defectdiastasis of at least $15 \%$ of original tibial length $(2.5 \mathrm{~cm})$ was simulated by resection of fragment ends reaching

미 Mokhovikov D.S., Stupina T.A., Varsegova T.N., Diuriagina O.V., Emanov A.A., Borzunov D. Yu. Histomorphometric characteristics of the tibialis anterior muscle and the peroneal nerve in experimental repair of post-resection tibial defect using the Ilizarov external fixation and the Masquelet technique. Genij Ortopedii, 2020, vol. 26, no 2, pp. 216-221. DOI 10.18019/1028-4427-2020-26-2-216-221 
a healthy and viable bone, by excision of scars and cartilaginuous excrescences performed at the second stage of the experiment. A cement spacer was introduced into the gap creating a tight bone-spacer-bone seal. The spacer was removed after 30 days and transverse osteotomy produced in the distal tibia to commence distraction after a 7-day latency period with the rate of 1 $\mathrm{mm}$ performed 4 times/day during 25-28 days to ensure docking of bone fragments at the site of defect-diastasis. The frame was taken off after 60-day fixation. Animals were sacrificed after 60-day fixation $(\mathrm{F} 60, \mathrm{n}=5)$ and 30 days after frame removal (FR30, $n=5)$. Animal care and all experimental procedures were in accordance with the European Convention for the protection of vertebrate animals used for experimental and other scientific purposes and Directive 2010/63/EU of the European Parliament and of the Council of 22 September 2010 on the protection of animals used for scientific purposes. The animals were provided humane care and treatment in compliance with SP 2.2.1.3218-14 "Sanitary and epidemiological requirements for the design, equipment and maintenance of experimental biological clinics (vivariums)", GOST 33215-2014 Guidelines for the maintenance and care of laboratory animals. Rules for equipment of premises and organization of procedures, GOST 33217-2014 Guidelines for the maintenance and care of laboratory animals. Rules for the maintenance and care of laboratory carnivores. The study received a favourable opinion from the relevant research ethics committee (Abstract of minutes № 2 (57) dtd 17.05.18).

Samples were taken from the tibialis anterior muscle (TAM) and the superficial peroneal nerve $(\mathrm{PN})$ at the level of the middle third of the tibia for morphological analysis. Specimen were fixed in a mixture of glutaraldehyde and paraformaldehyde in a phosphate buffer $\mathrm{pH} 7.4$ with addition of picric acid and embedded in paraffin using routine practice. Longitunal and transverse paraffin sections were stained with hematoxylin and eosin, and Masson's trichrome. Tissues from PN were post-fixed with $1 \%$ osmium (IV) oxide and embedded in epoxy resin. Semi-thin sections $1 \mu \mathrm{m}$ thick were stained with methylene blue basic fuchsin and toluidine blue. Images of micropreparations were acquired with AxioCam digital camera and AxioScope. A1 microscope (Carl Zeiss MicroImaging $\mathrm{GmbH}$, Germany). Muscle fiber degeneration (in \%) was identified on full-color images of longitudinal TAM sections (200 muscle fibers analyzed), and mean diameter of each fiber was measured on transverse sections at magnification of 500×. Histograms were built to distribute muscle fibers by diameters, and mean muscle fiber diameter (Dmv), number density of microvessels and muscle fibers, index of vascularization (Iv) were calculated for the sample of each series.

Number density of endoneurial microvessels, myelinated and non-myelinated nerve fibers was calculated using full-color images of total transverse sections of PN and recounted per $1 \mathrm{~mm} 2$ of the bundle area, and reactive destructive changes in the myelinated fibers (in \%), mean fiber diameter were measured using VideoTesT Master-Morphologiya software and distribution histograms prepared with an interval of $1 \mu \mathrm{m}$. TAMs and PNs of intact mongrel were used as controls $(n=5)$. Non-parametric Wilcoxon statistical test was used for independent samples with the level of statistical significance (p) quoted being equal to 0.05 . Statistical data analysis was performed using AtteStat computer program, version 9.3.1. [30].

\section{RESULTS}

General condition of the animals was satisfactory throughout the experiment. The operated segment appeared to be swollen after each intervention at early postoperative period. Supportability of the limb was rather weak throughout distraction and fixation phases. The limb function partially recovered after frame removal. Most TAM fibers retained regular transverse striation throughout the experiment (Fig. 1 a, c)

A part of muscle fiber bundles showed thickened and fibrous perimysium, perivascular fibrosis and some muscle bundles demonstrated endomysial fibrosis (Fig. 1 b, d) and adipose substitution (Fig. 1 a, c). A narrowing of the vascular lumen was seen in the perimysium due to the hyperplastic media. There were fibers with changed tinctorial characteristics, low colour intensity in the central areas of the fibers (Fig. 1b) and several profiles with angulation (Fig. 1 b, c). Areas of atrophy and death of myons featured decreased and rounded myons partially being at different phases of necrotic death (Fig. 1 b). There were myons with center- located nuclei (Fig. 1 d). Longitudinal blood vessels appeared to be more twisted around muscle fibers and a great number of circularly oriented vessels revealed. Clusters of muscle nuclei were noted in the areas of muscle fiber destruction, and newly formed small muscle fibers with center-located nuclei observed. Muscle fiber degeneration was $26.9 \%$ at F60 and $32.5 \%$ at FR30 and was not more than $1 \%$ in the intact muscle. Index of vascularization showed increase in the animals throughout the experiment as compared to that in controls (1.4): by $25 \%$ at F60 measuring $1.75(\mathrm{p}<0.05)$, and there was a 2-fold increase at the end of experiment measuring $2.8(\mathrm{p}<0.05)$. Mean muscle diameter showed a 2-fold decline as compared to the normal value $(43.5 \pm 0.82 \mu \mathrm{m})$ and measured $22.9 \pm 0.63 \mu \mathrm{m}(\mathrm{p}<0.05)$ at F60 and $22.4 \pm 0.72 \mu \mathrm{m}$ $(\mathrm{p}<0.05)$ at FR30. Histograms distributing the muscle fiber diameters at F60 and FR30 were nearly identical and had a unimodal distribution with sharp peaks instead of plateau observed in controls (Fig. 2). 


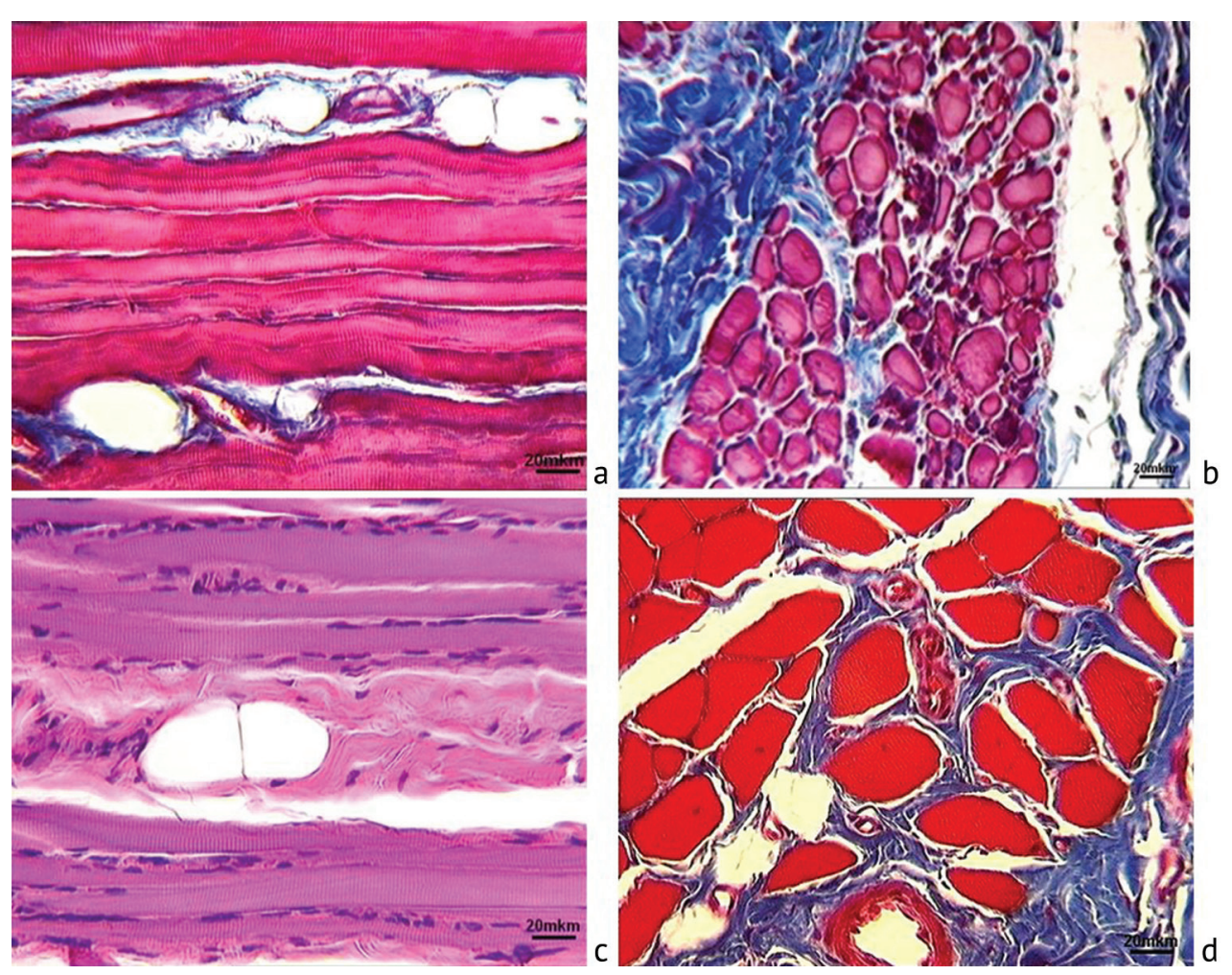

Fig. 1 Fragments of TAM at 60-day fixation $(\boldsymbol{a}, \boldsymbol{b})$ and after 30 days of frame removal $(\boldsymbol{c}, \boldsymbol{d})$. Paraffin sections stained with Masson's trichrome $(\boldsymbol{a}, \boldsymbol{d})$ and hematoxylin and eosin $(\boldsymbol{b}, \boldsymbol{c})$. Magnification of $400 \times$

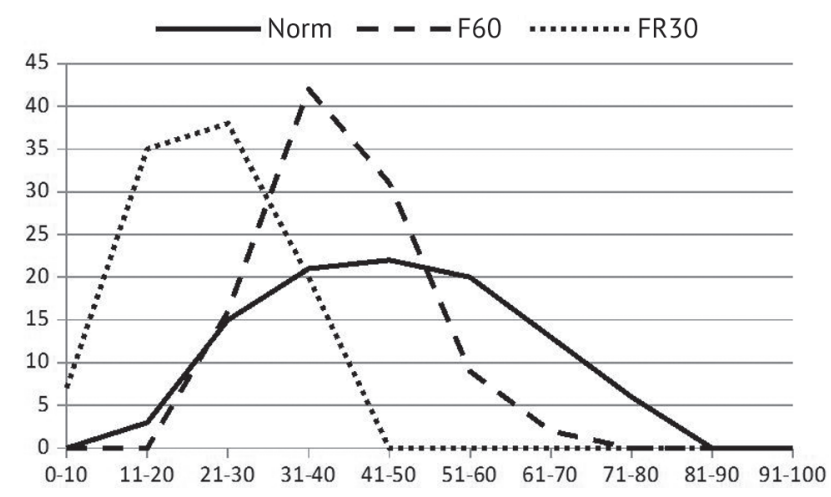

Fig. 2 Diagram of distribution of the muscle fiber diameters of intact and experimental TAM $(\mu \mathrm{m})$. X-axis shows dimensional fiber classes and Y-axis demonstrates the proportion of fibers in each class (\%)

The peak of the histogram was compatible with 31-40 $\mu \mathrm{m}$ class in $42 \%$ of muscle fibers at F60 with the amplitude of the base decreased by 1 class as compared to that in controls. There was no class of $71-80 \mu \mathrm{m}$ and over noted at F60. The peak of the histogram skewed to the left by 2 classes with the amplitude of the base decreased by 4 classes as compared to that in controls at FR30. There were no muscle diameters of $41-50 \mu \mathrm{m}$ and over observed at FR30 that this indicated to decrease in the mean diameter of the majority of muscle fibers. Macroscopic examination of PN during preparation and excision showed no disturbed interruption of the nerve at the study terms of the experiment. Macroscopic examination of the nerve sheaths demonstrated increased concentration of fibroblasts, fibrocytes, adipose and perivascular cells at F60 and FR30 and there were also plasmocytes and macrophages not typical for the intact PN observed at the time. Epineural arteries and veins were surrounded by strong connective tissue sleeves and had thickened walls, expanded or completely obliterated lumens (Fig. 3A, b). Perineurium appeared to be normally structured, thickened with subperineurial and endoneurial edema noted in some muscle bundles. Small myelinated fibers were seen in the conduction portion of the PN and in the regeneration clusters (Fig. 3 c). All animals showed changes in the myelinated fibers and signs of demyelinization, axonal and Wallerian degeneration.

Their proportion increased by 2.3 times as compared to intact nerves and measured $5.4 \pm 0.1 \%$ (normal $1.9 \pm 0,3 \%$ ) at F60, decreased to $4.0 \pm 0.5 \%$ but increased by 2.1 times as compared to normal value at FR30. Number density of the myelinated fibers insignificantly decreased by $5.6 \%$ as compared to that of the intact PN $(21335 \pm 1130)$ and measured $20147 \pm 2206$ at F60 and was significantly increased ( $\mathrm{p}<0.05$ ) by $10.1 \%$ of the normal value to measure $23500 \pm 618$ at FR30. Similar dynamics in number density of endoneurial microvessels showed a 1.9 times decrease in capillaries measuring $116 \pm 33$ (normal value $220 \pm 17$ ) at F60 and a 1.8 times increase of normal value measuring $400 \pm 134$ in $1 \mathrm{~mm}^{2}$ of the bundle at FR30. Number density of the myelinated fibers decreased by $39.4 \%(\mathrm{p}<0.05)$ and measured $9984 \pm 2317$ (normal value $16479 \pm 1944$ ) at F60 and increased with regard to the previous term but remained decreased by $5.9 \%$ of the normal value $(p<0.05)$ measuring $15500 \pm 905$ at FR30. 

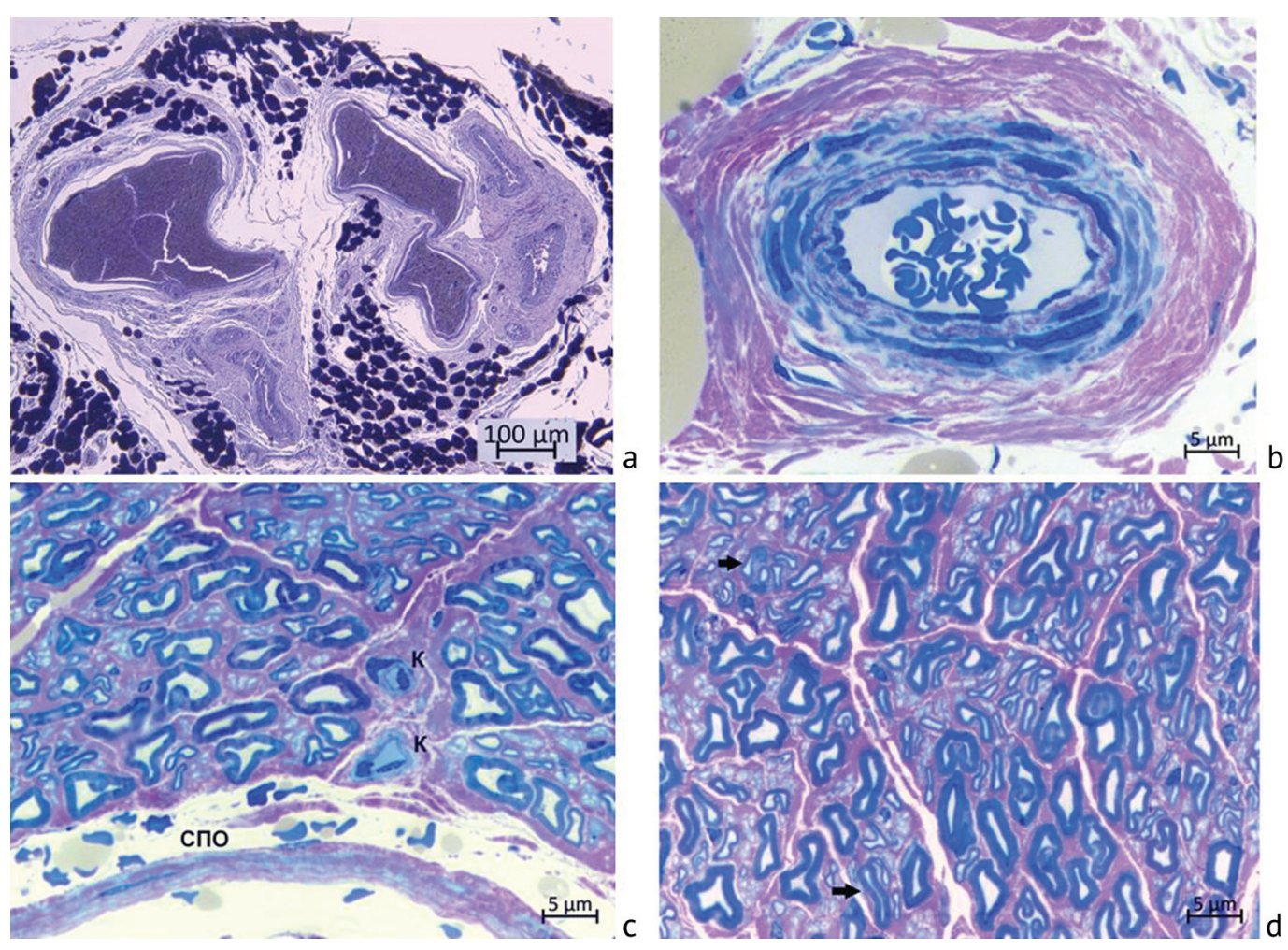

Fig. 3 PNs of mongrels at 60-day fixation of tibia with frame on: $(\boldsymbol{a})$ total cross section; $(\boldsymbol{b})$ epineurial artery and hypertrophied adventitia; $(\boldsymbol{c}, \boldsymbol{d})$ fragment of the nerve fiber bundle and subperineurial swelling (CПO), endoneurial capillaries (k) and regeneration clusters (arrows). Semi-thin sections stained with toluidine blue $(\boldsymbol{a})$, methylene blue and basic fuchsin $(\boldsymbol{b}, \boldsymbol{c}, \boldsymbol{d})$. Magnification $40 \times(\underline{\mathbf{a}})$; magnification $1000 \times(\boldsymbol{b}, \boldsymbol{c}, \boldsymbol{d})$

Histograms of distribution of muscle fiber diameters at F60 and FR30 retained bimodal pattern and contained 11 grades like intact PN (Fig. 4). The amplitudes of the base skewed to the left by 1 grade due to the presence of small regenerating fibers with diameter of 1.0-2.0 $\mu \mathrm{m}$. Histograms were shorter to the right by 1 grade with the absence of larger fibers with diameter of 12.1-13.0 $\mu \mathrm{m}$ (Fig. 4). The first mode skewed to the left in the range of 3.1-4.0 $\mu \mathrm{m}$ (normal value 4.1-5.0 $\mu \mathrm{m}$ ) and exceeded the normal value due to changes in the population of nerve conduction. Smaller fibers with diameter of 1.0-4.0 $\mu \mathrm{m}$ showed a 1.8 and 1.6 times increase at F60 and FR30 as compared to normal value (intact $\mathrm{PN}, 23 \pm 5 \%$ ); larger fibers showed a 1.7 and 1.6 times decrease (intact PN, $40 \pm 6 \%$ ), respectively, and medium sized fibers showed nearly normal measurements (normal $37 \pm 4 \%$ ) at F60 and FR30. Nerve fibers with fast conduction velocity having diameters of more than $10 \mu \mathrm{m}$ were singular throughout the experiment and measured $3 \%$ and $4 \%$ at F60 and FR30, respectively, (normal 8-10 \%).

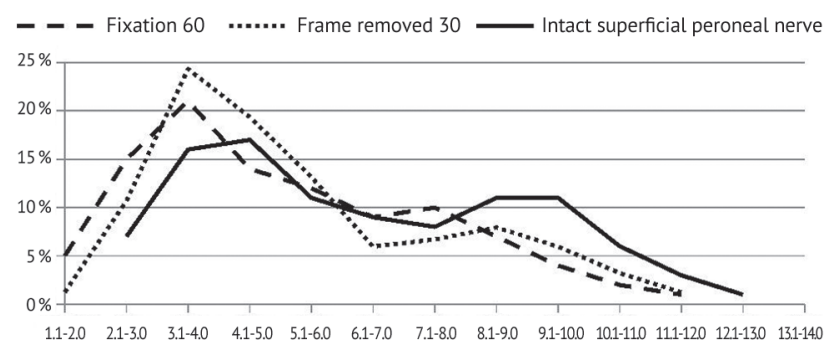

Fig. 4 Histograms of distribution of the myelinated nerve fiber diameters of intact and experimental PN $(\mu \mathrm{m})$. X-axis shows dimensional fiber classes and Y-axis demonstrates the proportion of fibers in each class (\%)

\section{DISCUSSION}

Reconstruction of extensive traumatic bone defects is still a major therapeutic challenge, both for anatomical and functional results [16]. Histomorphometric analysis of the TAM in the treatment of tibial defects using the above method showed muscle fiber degeneration of $32.5 \%$ in the experimental group and $1 \%$ in the controls. Histological changes in the TAM revealed myon death and adipose substitution, decreased size of the fibers, angulated fiber contours and were suggestive of denervated TAM. The peak of the histogram of distribution of MF diameters at F60 retaining the unimodal pattern indicated to previous ischemization of the muscle, and a 2-fold decrease in muscle diameter with regard to the mean value and the histogram skewed to the left by 4 classes showed an increase in muscle atrophy. Long-term exposure to hypoxia caused by trauma (intraoperative, bone trasport) is known to have detrimental effects on muscle structure $[17,18]$. Index of vascularization demonstrated high values throughout the experiment. Increase in the number density of microvessels is likely to be caused 
by topographic vascular redistribution in sections of atrophied muscle [19, 20]. Histomorphometric analysis of the PN showed reactive destructive changes in the form of demyelinated axons, their atrophy and Wallerian degeneration noted in at least $5.4 \%$ of myelinated nerve fibers at F60 and FR30. Similar reactive destructive changes in PNs were observed in experimental tibial lengthening [21, 22] and simulated comminuted fractures simulated in mongrels [23, 24]. A 1.6-to-1.7 times decrease in larger and a 1.6-to-1.8 times increase in smaller nerve fibers, the presence of regenerative fibers with diameter of less than $2 \mu \mathrm{m}$ indicated to previous destruction of a large number of motor and sensory nerves. Khabirov
F.A. [25] reported palsy of the PN in $61 \%$ of trauma and orthopaedic patients who underwent surgical interventions on tibia [26]. Changes in the population structure, destruction of myelinated fibers and loss of non-myelinated fibers with the use of the above technique were associated with microcirculation disorders caused by obliteration of epineurial vessels and loss of endoneurial capillaries. In contrast to the tibial and the sciatic nerves, the susceptibility of the common peroneal nerve to injury from a variety of causes may be explained by the tenuous nature of its intrinsic blood supply [27]. Hypervascularity of the endoneurium at the end of the experiment indicated to compensatory arterio- and capillarogenesis.

\section{CONCLUSION}

Signs of denervation and ischemization of the TAM, microcirculation disorders, destruction and loss of nerve fibers of the PN caused by radical debridement and prolonged time associated with the technique of tibial bone transport should be considered in planning of postoperative rehabilitation.

\section{REFERENCES}

1. Masquelet A.C., Obert L. Induced membrane technique for bone defects in the hand and wrist. Chir. Main, 2010, vol. 29, no. Suppl. 1, pp. S221-S224. DOI: 10.1016/j.main.2010.10.007.

2. Han W., Shen J., Wu H., Yu S., Fu J., Xie Z. Induced membrane technique: Advances in the management of bone defects. Int. J. Surg., 2017, vol. 42, pp. 110-116. DOI: 10.1016/j.ijsu.2017.04.064.

3. Masquelet A.C. Induced Membrane Technique: Pearls and Pitfalls. J. Orthop. Trauma, 2017, vol. 31, pp. S36-S38. DOI: 10.1097/ BOT.0000000000000979.

4. Mauffrey C., Hake M.E., Chadayammuri V., Masquelet A.C. Reconstruction of long bone infections using the induced membrane technique: Tips and tricks. J. Orthop. Trauma, 2016, vol. 30, no. 6, pp. e188-e193. DOI: 10.1097/BOT.0000000000000500.

5. Taylor B.C., French B.G., Fowler T.T., Russell J., Poka A. Induced membrane technique for reconstruction to manage bone loss. J. Am. Acad. Orthop. Surg., 2012, vol. 20, no. 3, pp. 142-150. DOI: 10.5435/JAAOS-20-03-142.

6. Mathieu L., Bilichtin E., Durand M., De l’Escalopier N., Murison J.C., Collombet J.-M., Rigal S. Masquelet technique for open tibia fractures in a military setting. Eur. J. Trauma Emerg. Surg., 2019. DOI: 10.1007/s00068-019-01217-y.

7. Raven T.F., Moghaddam A., Ermisch C., Westhauser F., Heller R., Bruckner T., Schmidmaier G. Use of Masquelet technique in treatment of septic and atrophic fracture nonunion. Injury, 2019, vol. 50, no. Suppl. 3, pp. 40-54. DOI: 10.1016/j.injury.2019.06.018.

8. Wang J., Yin Q., Gu S., Wu Y., Rui Y. Induced membrane technique in the treatment of infectious bone defect: A clinical analysis. Orthop. Traumatol. Surg. Res., 2019, vol. 105, no. 3, pp. 535-539. DOI: 10.1016/j.otsr.2019.01.007.

9. Masquelet A.C., Kishi T., Benko P.E. Very long-term results of post-traumatic bone defect reconstruction by the induced membrane technique. Orthop. Traumatol. Surg. Res., 2019, vol. 105, no. 1, pp. 159-166. DOI: 10.1016/j.otsr.2018.11.012.

10.Borzunov D.Y., Gorbach E.N., Mokhovikov D.S., Kolchin S.N. Kombinirovannye kostnoplasticheskie vmeshatelstva pri reabilitatsii patsientov s vrozhdennym lozhnym sustavom kostei goleni [Combined bone plasty interventions for rehabilitation of patients with congenital pseudarthrosis of the tibia]. Genij Ortopedii, 2019, vol. 25, no. 3, pp. 304-311. (in Russian)

11.Abdulazim A.N., Reitmaier M., Eckardt H., Osinga R., Saxer F. The Masquelet technique in traumatic loss of the talus after open lateral subtalar dislocation - A case report. Int. J. Surg. Case Rep., 2019, vol. 65, pp. 4-9. DOI: 10.1016/j.ijscr.2019.10.029.

12.Moteki T., Yanagawa T., Saito K. Autograft treated with liquid nitrogen combined with the modified Masquelet technique for bone defect after resection of malignant bone tumors: Two case reports. J. Orthop. Sci., 2019, vol. 24, no. 3, pp. 573-577. DOI: 10.1016/j. jos.2017.01.001.

13.Morelli I., Drago L., George D.A., Romanò D., Romanò C.L. Managing large bone defects in children: a systematic review of the 'induced membrane technique'. J. Pediatr. Orthop. B, 2018, vol. 27, no. 5, pp. 443-455. DOI: 10.1097/BPB.0000000000000456.

14.Morwood M.P., Streufert B.D., Bauer A., Olinger C., Tobey D., Beebe M., Avilucea F., Buitrago A.R., Collinge C., Sanders R., Mir H. Intramedullary Nails Yield Superior Results Compared with Plate Fixation When Using the Masquelet Technique in the Femur and Tibia. J. Orthop. Trauma, 2019, vol. 33, no. 11, pp. 547-552. DOI: 10.1097/BOT.0000000000001579.

15.Giotikas D., Tarazi N., Spalding L., Nabergoj M., Krkovic M. Results of the Induced Membrane Technique in the Management of Traumatic Bone Loss in the Lower Limb: A Cohort Study. J. Orthop. Trauma, 2019, vol. 33, no. 3, pp. 131-136. DOI: 10.1097/ BOT.0000000000001384.

16.Morelli I., Drago L., George D.A., Gallazzi E., Scarponi S., Romanò C.L. Masquelet technique: myth or reality? A systematic review and meta-analysis. Injury, 2016, vol. 47, no. Suppl. 6, pp. S68-S76. DOI: 10.1016/S0020-1383(16)30842-7.

17.Hoppeler H., Vogt M. Muscle tissue adaptations to hypoxia. J. Exp. Biol., 2001, vol. 204, pt. 18, pp. 3133-3139.

18.Shchudlo N.A., Shchudlo M.M., Borisova I.V., Filimonova G.N. Gistologicheskie izmeneniia perednei bolshebertsovoi myshtsy pri udlinenii goleni sobak s povyshennym sutochnym tempom distraktsii razlichnoi drobnosti [Histological changes in the anterior tibial muscle for canine leg lengthening with the increased daily rate of different-division distraction]. Genij Ortopedii, 2013, no. 3, pp. 71-76. (in Russian) 
19.Čebašek V., Kubínová L., Janáček J., Ribarič S., Eržen I. Adaptation of muscle fibre types and capillary network to acute denervation and shortlasting reinnervation. Cell Tissue Res., 2007, vol. 330, no. 2, pp. 279-289. DOI: 10.1007/s00441-007-0484-5.

20.Čebašek V., Eržen I., Vyhnal A., Janáček J., Ribarič S., Kubínová L. The estimation error of skeletal muscle capillary supply is significantly reduced by 3D method. Microvasc. Res., 2010, vol. 79, no. 1, pp. 40-6. DOI: 10.1016/j.mvr.2009.11.005.

21.Shchudlo N., Varsegova T., Stupina T., Shchudlo M., Saifutdinov M., Yemanov A. Benefits of Ilizarov automated bone distraction for nerves and articular cartilage in experimental leg lengthening. World J. Orthop., 2017, vol. 8, no. 9, pp. 688-696. DOI: 10.5312/ wjo.v8.i9.688.

22.Shchudlo N.A., Varsegova T.N., Shchudlo M.M., Stepanov M.A., Yemanov A.A. Causes of peroneal neuropathy associated with orthopaedic leg lengthening in different canine models. Strategies Trauma Limb Reconstr., 2018, vol. 13, no. 2, pp. 95-102. DOI: 10.1007/s11751-018-0313-2.

23.Varsegova T.N., Shchudlo N.A., Shchudlo M.M., Saifutdinov M.S., Stepanov M.A. The effects of tibial fracture and Ilizarov osteosynthesis on the structural reorganization of sciatic and tibial nerves during the bone consolidation phase and after fixator removal. Strategies Trauma Limb Reconstr., 2015, vol. 10, no. 2, pp. 87-94. DOI: 10.1007/s11751-015-0227-1.

24.Varsegova T.N., Shchudlo N.A., Shchudlo M.M., Stepanov M.A., Saifutdinov M.S. Strukturnaia reorganizatsiia sedalishchnogo i bertsovykh nervov v period osteosinteza pereloma kostei goleni i posle ego konsolidatsii [Structural reorganization of the sciatic nerve and tibiofibular ones during osteosynthesis of the leg bone fracture and after its consolidation]. Annaly Klinicheskoi $i$ Eksperimentalnoi Nevrologii, 2016, vol. 10, no. 1, pp. 35-40. (in Russian)

25.Khabirov F.A. Klinicheskie varianty peronealnoi nevropatii [Clinical variants of peroneal neuropathy]. Prakticheskaia Meditsina, 2014, vol. 78, no. 2, pp. 7-17. (in Russian)

26.Simpson A.H., Halliday J., Hamilton D.F., Smith M., Mills K. Limb lengthening and peripheral nerve function-factors associated with deterioration of conduction. Acta Orthop., 2013, vol. 84, no. 6, pp. 579-584. DOI: 10.3109/17453674.2013.859418.

27.Ugrenovic S.Z., Jovanovic I.D., Kovacevic P., Petrović S., Simic T. Similarities and dissimilarities of the blood supplies of the human sciatic, tibial, and common peroneal nerves. Clin. Anat., 2013, vol. 26, no. 7, pp. 875-882. DOI: 10.1002/ca.22135.

Received: 14.02.2020

\section{Information about the authors:}

1.Denis S. Mokhovikov, M.D., Ph.D., Ilizarov National Medical Research Centre for Traumatology and Orthopedics, Kurgan, Russian Federation

2. Tatyana A. Stupina, Ph.D. of Biological Sciences, Ilizarov National Medical Research Centre for Traumatology and Orthopedics, Kurgan, Russian Federation, Email: StupinaSTA@mail.ru

3. Tatyana N. Varsegova, Ph.D. of Biological Sciences, Ilizarov National Medical Research Centre for Traumatology and Orthopedics, Kurgan, Russian Federation, Email: varstn@mail.ru

4. Olga V. Diuriagina, Ph.D. of Veterinary Sciences, Ilizarov National Medical Research Centre for Traumatology and Orthopedics, Kurgan, Russian Federation, Email: diuriagina@mail.ru

5. Andrey A. Emanov, Ph.D. of Veterinary Sciences, Ilizarov National Medical Research Centre for Traumatology and Orthopedics, Kurgan, Russian Federation

6. Dmitry Yu. Borzunov, M.D., Ph.D.,

Ural State Medical University, Ekaterinburg, Russian Federation,

Central City Clinical Hospital, Ekaterinburg, Russian Federation,

Email: borzunov@bk.ru 